\title{
Natural Edible Oils: Comparative Health Aspects Of Sesame, Coconut, Mustard (Rape Seed) and Groundnut (Peanut) A Biomedical Approach
}

\author{
* Rashmi Sharma and Arun Kumar Sharma \\ Department of Chemistry, SPC Govt College, Ajmer-305901 Rajasthan India
}

Received: October 05, 2017 Published: October 16, 2017

*Corresponding author: Rashmi Sharma, Department of Chemistry, S.P.C. Govt College, Ajmer, Rajasthan, India 305001

\section{Introduction}

Fats and Oils are one of the large groups of organic compounds which are of great importance in the food. We eat oils because they are readily digested and utilized in the body. The chief contribution of fats and other lipids to the diet is their energy value and also satiety value. Fats and other lipids also contribute essential fatty acids to the diet which body cannot synthesized .Fats are also act as solvents for the fat soluble vitamins such as A,D,E and $K$ and the protamine At, the Carotene. The Fats and lipids are therefore important in the diet for number of reasons. Edible oils have significant role in diet all around the world especially in India as Indian culture is based on idealism of well beings of all creatures of the earth.

Edible oils are related directly to the health aspects of all the people and also to the farmers and businessmen. From long time according to the environment of the Local region and area, various natural oil seeds like sesame mustard, ground nut and coconut have been cultivated as a source of best fat in the different countries especially in India. The oil has been extracted through eco- friendly cold pressing technique called 'Ghani' which extract the oil from seed very slowly at low velocity and room temperature. The extracted oil is fresh, healthy, pure, and nutritious with natural color, flavor and odor.

Traditional oils like Sesame, Coconut, Mustard and Groundnut oils are being used in India from long time, which may be used in cooking vegetables, deep frying and for storage purposes as pickles , therefore the fact is that mostly oil is treated at high temperature or stored for long period. Literature survey reveals that rancidity and reversion are found to be the major problems in the use of vegetable oils, which are caused due to tendency of unsaturated fatty acids to oxidize during thermal treatment and storage. This may be attributed to the fact that oil containing more poly unsaturation (PUFA) reacts more rapidly with air and rancidity and reversion like phenomenon takes place readily. Some other reactions like Oxidative polymerization and hydrogenation can occur during their thermal abuse and longer storage.
According to literature of ancient Ayurveda sesame oil is the best for edible purposes and which has been used as dressing oil on freshly cooked traditional food items made by regional food grains which are very nutritious in all means, though mustard, groundnut and coconut oils are not only healthy but possess medicinal properties as well [1,2] whereas Safflower oil is said worst for eaten as an oil [1]. In the last few years these native edible oils have been supplanted by introducing recent oils such as palm, soybean, sunflower and safflower which have never been used in any part for traditional nutritious food of local region in world and India. Indepth scientific studies of these oils support traditional (Ayurveda) understanding and indicate that these new oils extracted and treated chemically are not only undesirable but are harmful for health, especially in Indian cuisine where they are mostly used for frying and for pickles.

Thus it is generally accepted that oils with a higher percentage of polyunsaturated fatty acids (PUFA) such as soybean, sunflower and safflower (highest content of PUFA present) lower both harmful LDL cholesterol and useful HDL cholesterol. On the other hand edible oils rich in monounsaturated fatty acids such as olive, mustard, groundnut, and sesame lower harmful LDL cholesterol level without affecting useful HDL cholesterol and hence are better for balancing cholesterol profiles [3-11]. According to Tewfik I.H., Ismail H.M., Surnars of Dep't of Nutrition University of Alexandria, Egypt, ingestion of decomposition products formed as a result of thermal abuse and oxidation of frying oils are known to lead to a variety of symptoms and diseases such as allergies, atherosclerosis, and coronary heart diseases etc [6].

According to H. Ester Bauer of Institute of Bio-chemistry, University of Graz, Austria, experimental animal studies and Bio Chemical investigations lead support to the hypothesis that lipid oxidation products, ingested with food or produced endogenously, represent a health risk, chronic uptake of large amount of such materials increases tumor frequency and incidence of atherosclerosis in animals [8]. Moreover, additional cholesterol- 
reducing properties are likely to come from the natural plant sterols and stanols contained in oils extracted without heat or solvents $[2,12]$. Sesame contains $594 \mathrm{mg} / 100 \mathrm{~g}$ of soluble phyto-sterols while groundnut contains $247 \mathrm{mg} / 100 \mathrm{~g}$ and olive oil $210 \mathrm{mg} / 100 \mathrm{~g}$. Soya and corn oils also contain phyto-sterols when raw $(380 \mathrm{mg} / 100 \mathrm{~g}$ and $580 \mathrm{mg} / 100 \mathrm{~g}$ respectively), but since these latter need solvent or heat for extraction, the sterols are invariably lost in processing [12].

The natural oils such as mustard, peanut and sesame are stable non-drying or semi-drying oils with a low tendency to oxidize in the light. In their natural form they contain antioxidants which prevent rancidity and reversion (development of 'off' odors). In contrast, soybean and safflower oil are drying oils while sunflower oil is semidrying oil. Thus, due to a higher percentage of PUFAs they are prone to oxidation in the presence of light, temperature, and air and metal. In cooking, since edible oils are mainly used for frying in which oil is subjected to light, high temperature and contact with air and metal; such oils are harmful to health.

In Western countries rancidity and reversion of refined oils such as soybean oil were initially remedied by hydrogenation. More recently, with growing evidence of the harmfulness of trans-fatty acids, rancidity and reversion are increasingly being prevented by the addition of antioxidants [11]. However, according to studies conducted on soybean oil by V.K. Tyagi and Pramod Kumar at Kanpur, deterioration of nutritional quality at high frying temperatures is rapid and added antioxidants are almost ineffective at retarding this $[13,14]$.

Vegetarians can easily achieve $n-6 / n-3$ ratio and ALNA ( $\alpha$-linolenic acids) intake by using ALNA rich edible oil as the cooking medium and also by increasing the intake of ALNA rich foods such as seasem, mustard coconut and groundnut freshly extracted through cold pressing method in the diet [15-17]. Sesame oil contains $\alpha$-tocopherol (vitamin E ) sesamol ,sesamin lignan etc. , $\mathrm{Mg}, \mathrm{Cu}, \mathrm{Ca}, \mathrm{Fe}, \mathrm{Zn}$ and vitamin $\mathrm{B} 6$ which are very useful metals and vitamins Copper provides relief for rheumatoid , arthritis , $\mathrm{Mg}$ supports vascular and respiratory health calcium helps prevent colon cancer phytic acid present in seed to protect colon cancer, osteoporosis, migrain and PMS..Zn promotes bone health. Sesame contains high quality protein $(25 \%)$ and is rich in Methionine [essential Amino acid] and seed is highly beneficial in the treatment of Piles [18-21].

Ground nuts are a good source possessing 30 essential nutrients and phyto nutrients like niacin, fiber, folate, $\mathrm{Mg}, \mathrm{Mn}$ and $\mathrm{P}$ and vitamin E $25 \%$ protein antioxidant polyphenols called p-coumaric acid-roasting can increase peanuts p-coumaric acid levels, boosting their overall antioxidant content by as much as $22 \%$. They are significant source of resvertrol and co-enzyme Q.10 Resvertrol antioxidant is a chemical studied for potential antiaging effects and also associated with reduced cardiovascular disease and reduce cancer risk [22-24].

Similarly Mustard seeds are also possess very good nutritional value as well as medicinal values .Number of scientific studies and Charak Samhita [1] and Sushrut Samhita (Indian Ayurvedic
Literature) suggests that the Glucosinolates, essential fatty acids like linoliec acid ((A) and $\alpha$ - linoliec acid (alna), antioxidants etc. are required by the body and should be taken from external sources from food or from supplements. The genus Brassica consists of 150 species which are cultivated as oil seed crops or as vegetables and fodder crops. Black mustard is used more as a condiment. B.Juncea or Indian mustard is used as an condiment or as an oil seed. The chemical composition of the spices documented shows that they contain fat, nitrogenous substances, fiber, volatile ,oil and isothio cyanates and related compounds .Protective effect against carcinogens probably due to isoniocyanate content which by virtue of its potent effect and enzymes ,enhances solubilization and elimination of carcinogens [25].

Benzyl isothio cyanates and indole 3-carbinol, which are present in cruciferous vegetables in high amounts induce the conjugating system and are more effective inhibitors. The anti mutagenic effects of mustard were also assessed by various scientists [26]. Mustard (B. campustris) and sesame are considered anti carcinogenic based on cyto toxic and tissue culture studies. Thus the plant kingdom and dietary substances appear to open up new fields of investigation in cancer research. In fact, greater reliance on a natural means of protection from a disease rather than chemoprevention appears to be a more promising approach towards Human beings all over the world and particularly in developing countries.

Recommended intake of fatty acids:

Total fat calories upper limit $=25-30 \%$

a) $\quad 8-10 \%$ should be SFA (21-27 g for adult man consuming 2400 kcal per day) Source -Coconut oil and Fat obtained traditionally through A2 type cow's milk by Fermenting and Churning at low speed called "Desi Ghee"

b) $5-8 \%(13-21 \mathrm{~g})$ from PUFA, sources -Sesame, Olive, Mustard etc.

c) Rest from MUFA-sources Olive, Mustard, and Groundnut etc.

A perusal of the oil statistics worldwide shows that the production of soyabean, sunflower oils and other are increasing but the production of the best oil seed i.e. sesame is not gaining attention in spite of its health benefits. Efforts should be made to promote native and natural oil seeds such as sesame, groundnut, mustard, olive and coconut which require less water and can be grown in suitable climatic conditions which are rich in oil content as compared to soybean, sunflower \& safflower.

\section{Conclusion}

a) Natural oil seeds being high in oil content more than (40$75 \%$ ) are easy to process with eco friendly and health friendly technologies. The sustainable agriculture of these oil seeds should be promoted.

b) For natural oils, refinement is undesirable process as most of the useful lecithin, tocopherols, vitamins and phytosterols are removed in the process. 
Safe and pure foods are the foods which nature provides and humans process with the least use of energy and no use of chemicals. We should honor the nature's law.

\section{References}

1. Charak Sanhita Part I (1975) Jaynendra Press New Delhi, India 27: 249.

2. Meyer, LH (1960) Food chemistry. Litton Educational Publishing, Inc. USA.

3. Sharma R, Khan S (2007) Health aspects of traditionally processed indigenous edible oils. Recent Progress in Medicinal Plants, Natural Products-II stadium, Press LLC, USA 18: 430.

4. Sharma R, R Bhutra, S Acharya, MRK Sherwani (2007) Comparative analysis of four edible oils for stability against longer storage and heat deterioration during frying. Jlipid sci and Technology 39: 3.

5. Hildich TP, PN William (1964) Chemical Constitution of Natural Fats. 4th edn. Chapman \& Hall, London.

6. Tewfilk IH, HM Ismail, S Sumar (1998) The effect of Intermittent heating on some chemical parameters of refined oils used in Egypt. A Public health nutrition concern. Int J Food Sci Nutr 49(5): 339-342.

7. Goburdun D, B Jhuree (1995) Effect of deep fat frying on fat oxidation in soyabean oil. Int J Food Sci Nutr 46(4): 363-371.

8. Esterbauer H (1993) Cytotoxicity and genotoxicity of lipid-oxidation products. Am J of Clinical Nutrition 57(5): 779S-785S.

9. Woodside JV, IS Young (2001) Dietary antioxidants and protection from coronary heart diseases. In: Nutritional Health: Strategies for disease prevention. Eds: Wilson T and Temple NI Humana Press, Totowa, USA.

10. Byers T (1997) Hardened fats, hardened arteries? New England. Journal of Medicine 337: 1543-1545.

11. Ascherio A, Katan MB, Stampfer MJ, Peter L Zock, Walter C Willett (1999) Trans fatty acids and coronary heart diseases. New England Journal of Medicine 340: 1994-1998.
12. Law M (2000) Plant sterol and stanol margarines and health. BMJ 320(7238): 861-864.

13. Tyagi VK, Vashishtha AK (1994) Effect of deep fat frying on the characteristics and composition of soyabean oil. J Oil Technologist's Association of India 26: 111.

14. Tyagi VK, Pramod Kumar (1995) Formation of polymeric fractions in frying fats. J Oil Technologist's Association of India 26: 363.

15. Shiva V (2000) Stolen Harvest: The Hijacking of the Global Food Supply. South End Press, Cambridge, MA.

16. RangaSwamy Baby Latha, Prabhdial Singh, Nasirullah (2008) J Lipid Sci and Technology 40(2): 59-64.

17. Nasirullah, Rangaswamy Baby latha (2009) J Lipid Sci and Technology 41(1): 10-14.

18. Yale J Biol Pred, Sankar D et al. (2006) Department of Bio Technology, Vinayaka Mission Research Foundation University, Paiyanoor chennai, India.

19. (2005) J Nutr Sci. Vitaminol, Tokyo 51(4): 223-230.

20. (2005 ) J Med. Food Fall 18(3): 377-381.

21. (2005) Alcohol Clin. Exp. Res 29(11): 116S-120S.

22. Peanuts : Worlds Healthiest foods, Wh foods Com.

23. Sanders TH, Mc Micheal RW, Hendrix KW (2000) "Occurance of resveratrol in edible peanuts "Journal of agriculture and food chemistry 48(4): 1243-1246.

24. (2007) “Coenzyme Q 10 “ American Cancer Society.

25. (2003) Clinical Versatility of Antioxidants and w-6/w-3 PUFA content in Edible Vegetable Oil- Shyam Prakash et al. National Convention on Health, Nutrition and value Addition, New Delhi, p. 22.

26. (2005) Food and Nutrition, Priya Bhargava, Tarachand, Commen Wealth Publishers, pp. 209- 2.

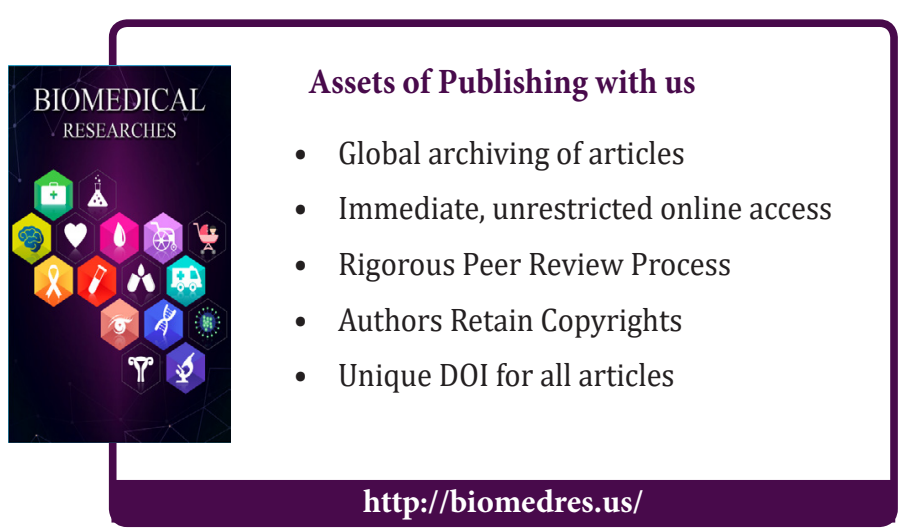

